\title{
Changing Patterns of Distant Metastasis in Patients With Lower Rectal Cancer Undergoing Intraoperative Radiotherapy
}

\author{
TADAHIKO MASAKI ${ }^{1}$, HIROYOSHI MATSUOKA $^{1}$, TOMOKAZU KISHIKI ${ }^{1}$, KOICHIRO KOJIMA $^{1}$, AYAKO TONARI $^{2}$, \\ NOBUYOSHI ASO ${ }^{1}$, AYUMI BENIYA ${ }^{1}$, AIKO IIOKA ${ }^{1}$, TAKASHI WAKAMATSU ${ }^{1}$ and EIJI SUNAMI ${ }^{1}$ \\ ${ }^{1}$ Department of Surgery, Kyorin University, Tokyo, Japan; \\ ${ }^{2}$ Department of Radiation Oncology, Kyorin University, Tokyo, Japan
}

\begin{abstract}
Background/Aim: Local radiotherapy for primary tumors may increase the incidence of distant metastasis. However, the patterns of target organs have not been clarified yet. Patients and Methods: In our randomized controlled trial examining the oncological efficacy of intraoperative radiotherapy (IORT) for advanced lower rectal cancer, the details of the metastatic organs were evaluated. Results: In the IORT group (38 patients), 2 patients had metastasis in the liver and lung simultaneously, 9 in the liver, and 4 in the lung. In the control group (38 patients), 3 had metastasis in the lung, and 2 in the liver. The IORT group tended to have liver metastases more frequently $(p=0.058)$. Among patients with liver metastases, distant metastasis-free intervals were significantly shorter in the IORT group, however, no significant difference was observed among patients with lung metastases. Conclusion: After curative rectal cancer surgery with IORT, liver metastasis may be increased and accelerated.
\end{abstract}

Even after curative resection, patients with advanced rectal cancer experience high incidence of distant metastasis (1-4). The distribution of metastatic organs varies according to the level of rectal cancer. Chiang et al. reported that the risk of lung, bone, and systemic lymph node metastasis was significantly higher in lower rectal cancer situated $0-5 \mathrm{~cm}$ from the anal verge compared with upper rectal cancer situated $10.1-15 \mathrm{~cm}$ from the anal verge (5). This

This article is freely accessible online.

Correspondence to: Dr. Tadahiko Masaki, MD, Department of Surgery, Kyorin University, 6-20-2, Shinkawa, Mitaka city, Tokyo, 181-8611, Japan. Tel: +81 422475511, Fax: +81 422479926, e-mail: masaki@ks.kyorin-u.ac.jp

Key Words: Lower rectal cancer, distant metastasis, intraoperative radiotherapy. phenomenon has been explained by differences in venous drainage with respect to tumor location. The upper rectum is drained into the superior rectal vein, which drains into the inferior mesenteric vein and then the portal vein, while the lower rectum is drained into the inferior rectal vein, which drains into the common iliac vein and the inferior vena cava. Therefore, upper rectal cancers most often metastasize to the liver, while lower rectal cancers to the lung.

In addition to the above-mentioned anatomical process, the affinity between tumor cells and target distant organs plays an important role in the establishment of tumor cell metastasis, which has long been accepted as the "seed and soil" theory (6).

In the last several decades, this theory has been validated by the development of molecular biology (7).

In our randomized controlled study to examine the oncological efficacy of intraoperative radiotherapy (IORT) for advanced lower rectal cancer (UMIN000021353), we noticed that IORT might increase the incidence of distant metastasis (8). In this study, the details of the metastatic organs were reviewed, and underlying mechanisms were considered.

\section{Patients and Methods}

The trial protocol, patients' demographic parameters, and oncological results have been reported previously (8). In brief, from March 2000 through July 2017, 40 cases were allocated to the IORT group and 39 cases to the control group. Written informed consent was obtained from all individual participants included in the study. This study was approved by our institutional review board (2003No.30). Two cases in the IORT group and one case in the control group were excluded, resulting in 38 cases in each group (Figure 1) (8). The average ( \pm standard error, SE) tumor distance from the anal verge was $4.5 \mathrm{~cm}( \pm 0.2 \mathrm{~cm})$ in the IORT group, and $4.7 \mathrm{~cm}( \pm 0.2$ $\mathrm{cm}$ ) in the control group, suggesting that all the tumors were located in the lower rectum. Pelvic autonomic nerve preservation (PANP) was categorized into complete, unilateral, and partial types. The unilateral and partial types were defined as the limited PANP. The control group underwent bilateral lateral lymph node dissection 


\section{Phase III RCT}

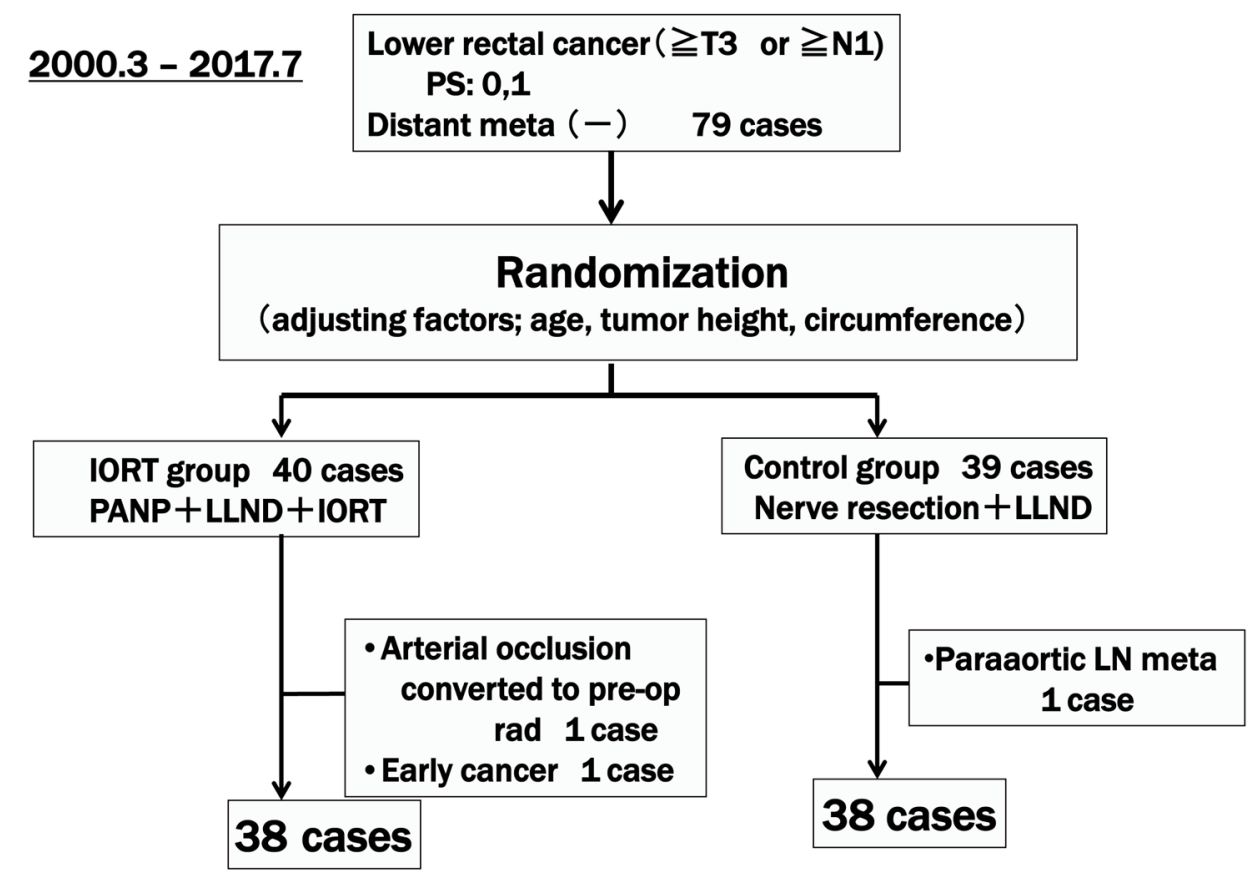

Figure 1. An algorithm of our trial [adapted from (8)].

Table I. Initial sites of distant metastasis.

\begin{tabular}{lcccccc}
\hline & None & Liver & Lung & Liver+lung & Distant LNs & Bone+distant LNs \\
\hline IORT group (38) & 22 & 9 & 4 & 2 & 1 & 0 \\
Control group (38) & 30 & 2 & 3 & 0 & 2 & 1 \\
\hline
\end{tabular}

LN: Lymph node; IORT: intraoperative radiotherapy. Likelihood ratio test; $p=0.058$.

(LLND) and limited PANP, while the IORT group underwent bilateral LLND, complete PANP, and IORT. In the IORT group, the cone size ranged from 3.8 to $5.1 \mathrm{~cm}$, and the energy and dose of the radiation used for each pelvic plexus ranged from 6 to $12 \mathrm{MeV}$ and from 18 to $20 \mathrm{~Gy}$, respectively (8).

Post-operative course of each patient was obtained from outpatient records with special reference to tumor recurrence, and recurrence sites were categorized into liver, lung, local, bone, brain, distant lymph nodes, and others. As has already been reported, distant metastasis-free survival rate was significantly lower in the IORT group (Figure 2) (8).

Statistical analysis. In this study, the distributions of recurrence sites were compared between the IORT group and the control group using chi-square test or Fisher's exact test. The distant metastasisfree interval (DMFI) with respect to metastatic sites of the two groups were compared using Student $t$-test. A $p$-value $<0.05$ was considered statistically significant.

\section{Results}

Table I shows the initial distant metastasis sites in both groups. In the IORT group, 2 patients had initial metastasis in the liver and lung simultaneously, and 9 patients in the liver only, while 4 patients in the lung only. On the other hand, in the control group, 3 patients had metastasis in the lung only, and 2 patients in the liver only. The IORT group tended to have liver metastases more frequently with marginal significance (likelihood ratio test; $p=0.058$ ).

When one exceptional case (case no. 54) was excluded from 11 patients with liver metastases, the DMFI was $95 \pm 24$ days in the IORT group ( 8 patients), and $228 \pm 47$ days in the control group ( 2 patients). There was a significant difference between the two groups $(p=0.037)$. On the other hand, among 7 patients with lung metastases, the DMFI was 


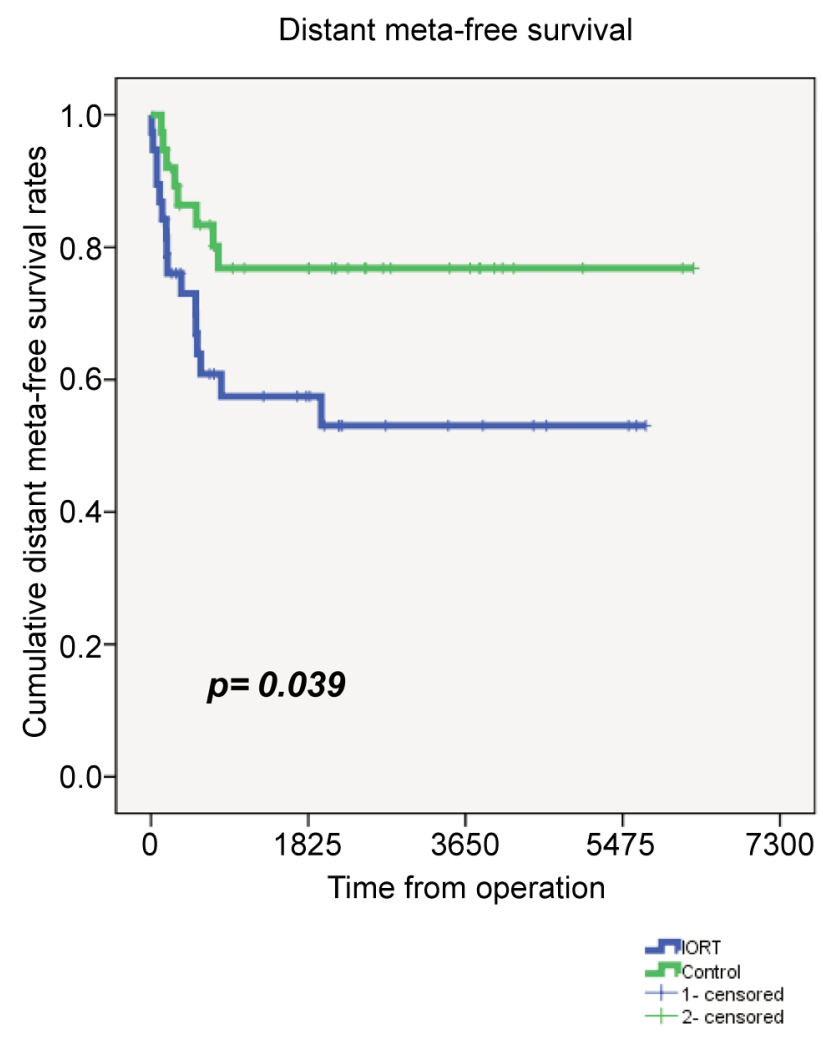

Figure 2. Kaplan-Meier curves of distant metastases-free survival showed a significant difference between the intraoperative radiotherapy $(I O R T)$ and the control groups $(p=0.039)$ [adapted from (8)].

$567 \pm 96$ days in the IORT group (4 patients), and $604 \pm 148$ days ( 3 patients) in the control group. There was no significant difference between the two groups (Figure 3).

\section{Discussion}

As Chiang et al. elegantly described, the risk of lung, bone, and systemic lymph node metastasis were significantly higher in lower rectal cancer situated $0-5 \mathrm{~cm}$ from the anal verge compared with upper rectal cancer situated $10.1-15 \mathrm{~cm}$ from the anal verge. Furthermore, among 117 patients with lower rectal cancers, lung, liver, bone, brain, and systemic LN metastases were seen in $38,12,13,4$, and 17 patients, respectively, showing that lung metastases were more frequent than liver metastases (5). In our study population, all the tumors were located in the lower rectum. However, contrary to our expectations, liver metastases occurred more frequently in the IORT group with marginal significance (likelihood ratio test; $p=0.058$ ). The precise mechanism of this unexpected phenomenon was unclear, however, it deserves to be discussed in more details.

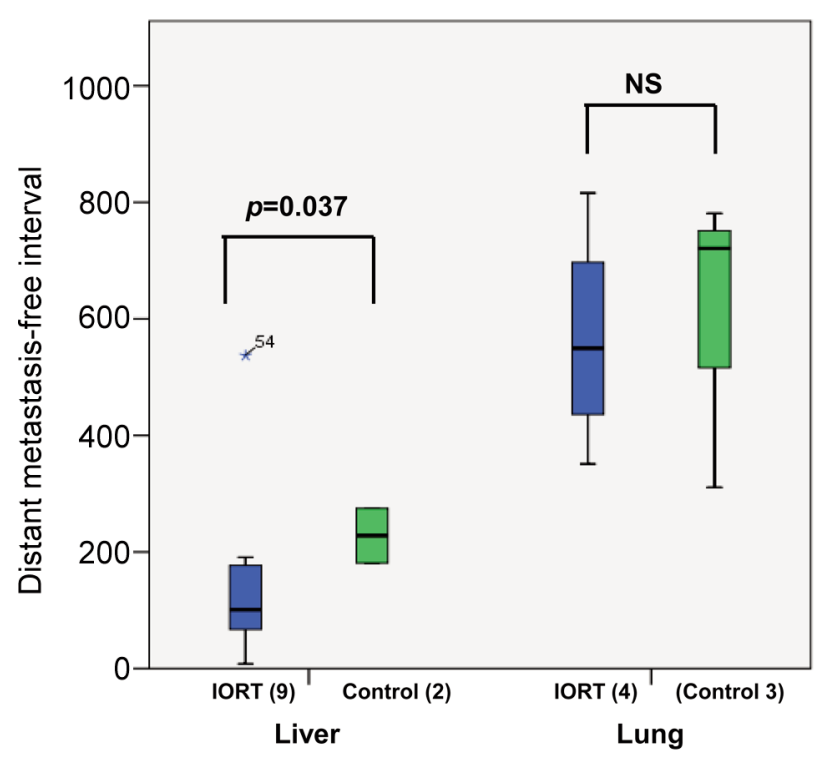

Figure 3. Distant metastasis-free interval (DMFI) and metastatic sites. When one exceptional case (case no. 54) was excluded from 11 patients with liver metastases, the DMFI was $95 \pm 24$ days in the intraoperative radiotherapy (IORT) group ( 8 patients), and $228 \pm 47$ days in the control group (2 patients), with a significant difference between the two groups ( $p=0.037$ ). Among 7 patients with lung metastases, the DMFI was $567 \pm 96$ days in the IORT group (4 patients), and $604 \pm 148$ days (3 patients) in the control group, with no significant difference between the two groups.

In Chiang et al.'s study population, patients undergoing preoperative neoadjuvant therapy, either short-course radiation therapy or long-course chemoradiation therapy, were excluded from the analysis (5). However, in our study population, the test group underwent IORT to the bilateral pelvic sidewall after total mesorectal excision and lateral lymph node dissection (18 to $20 \mathrm{~Gy}$ in each pelvic plexus) (8). In such a circumstance, the middle and inferior rectal veins (the drainage veins for lower rectal cancer) were already divided, and the direct route of lung metastasis was lost. Therefore, there was little possibility that IORT might push cancer cells into the drainage veins. Certainly, the IORT group had lung metastases with a similar frequency as the control group.

So, why were liver metastases more often seen in the IORT group?

There were only two randomized controlled studies examining why radiotherapy might increase the incidence of distant metastasis, one in oropharyngeal and hypopharyngeal cancers using short-course radiotherapy (SCRT) (9), and the other in pancreatic cancers using IORT (10). As compared with long-course radiotherapy, the patients' immunological conditions might be disturbed in either SCRT or IORT due to the greater radiation dose/fraction, and distant metastasis 
might be increased and accelerated (8). However, the distribution of target organs was not described in detail in these two studies.

To our knowledge, our study was the first clinical trial to reveal that IORT might increase and accelerate liver metastasis in patients with lower rectal cancer.

Some basic studies suggested that radiation enhances cancer cell migration and invasion (11-14). Among them, Saigusa et al. examined gene expression levels of hepatocyte growth factor $(H G F)$ and its receptor cMET in cancer cells, and $H G F$ expression in the stroma, using RTPCR in 53 rectal cancer patients after preoperative chemoradiotherapy (11). Interestingly, cancer cell HGF levels were significantly higher in the short-course radiotherapy group (42 patients; $0.270 \pm 0.044$ ) than in the long-course chemoradiotherapy group (11 patients; $0.049 \pm 0.015)(p=0.023)$. Furthermore, stromal HGF levels were significantly higher in the distant recurrence (+) group (8 patients; $0.122 \pm 0.095)$ than in the distant recurrence $(-)$ group (45 patients; $0.028 \pm 0.015)(p=0.018)$. Considering that induction of $\mathrm{HGF} / \mathrm{cMET}$ signaling promotes liver micrometastases in a mice model (15), our observation might be explained by a well-designed 'in vivo' experiment using high dose local radiation.

There are several limitations in this study. Although this was a prospective randomized controlled trial, it was conducted at a single institution, and the number of enrolled patients was small. Further accumulation of clinical and basic evidences will be mandatory.

\section{Conclusion}

After potentially curative rectal cancer surgery with IORT, the occurrence of liver metastasis may be increased and accelerated. Clinical and basic research will be mandatory to explain this unexpected phenomenon.

\section{Conflicts of Interest}

All Authors had no conflicts of interest to declare regarding this study.

\section{Authors' Contributions}

Study conception and design: Tadahiko Masaki, Ayako Tonari; Acquisition of data: Hiroyoshi Matsuoka, Tomokazu Kishiki, Koichiro Kojima, Nobuyoshi Aso, Ayumi Beniya, Aiko Iioka, Takashi Wakamatsu; Analysis and interpretation of data: Tadahiko Masaki; Drafting of manuscript: Eiji Sunami.

\section{Acknowledgements}

The Authors thank all of the participants of this trial and medical staff of Kyorin University Hospital.

\section{References}

1 Valentini V, van Stiphout RG, Lammering G, Gambacorta MA, Barba MC, Bebenek M, Bonnetain F, Bosset JF, Bujko K, Cionini L, Gerard JP, Rödel C, Sainato A, Sauer R, Minsky BD, Collette L and Lambin P: Nomograms for predicting local recurrence, distant metastases, and overall survival for patients with locally advanced rectal cancer on the basis of European randomized clinical trials. J Clin Oncol 29(23): 3163-3172, 2011. PMID: 21747092. DOI: 10.1200/JCO.2010.33.1595

2 Cottet V, Bouvier V, Rollot F, Jooste V, Bedenne L, Faivre J, Launoy $\mathrm{G}$ and Bouvier AM: Incidence and patterns of late recurrences in rectal cancer patients. Ann Surg Oncol 22(2): 520527, 2015. PMID: 25160733. DOI: 10.1245/s 10434-014-3990-1

3 Tan WJ, Tan HJ, Dorajoo SR, Foo FJ, Tang CL and Chew MH: Rectal cancer surveillance-recurrence patterns and survival outcomes from a cohort followed up beyond 10 years. J Gastrointest Cancer 49(4): 422-428, 2018. PMID: 28660522. DOI: $10.1007 / \mathrm{s} 12029-017-9984-\mathrm{z}$

4 Yamamoto $\mathrm{T}$, Kawada K, Hida K, Ganeko R, Inamoto S, Yoshitomi M, Watanabe T and Sakai Y: Optimal treatment strategy for rectal cancer based on the risk factors for recurrence patterns. Int J Clin Oncol 24(6): 677-685, 2019. PMID: 30721379. DOI: 10.1007/s10147-019-01400-6

5 Chiang JM, Hsieh PS, Chen JS, Tang R, You JF and Yeh CY: Rectal cancer level significantly affects rates and patterns of distant metastases among rectal cancer patients post curativeintent surgery without neoadjuvant therapy. World J Surg Oncol 12: 197, 2014. PMID: 24980147. DOI: 10.1186/1477-7819-12197

6 Paget S: The distribution of secondary growths in cancer of the breast. 1889. Cancer Metastasis Rev 8: 98-101, 1989. PMID: 2673568.

7 Langley RR and Fidler IJ: The seed and soil hypothesis revisited--the role of tumor-stroma interactions in metastasis to different organs. Int J Cancer 128(11): 2527-2535, 2011. PMID: 21365651. DOI: $10.1002 / \mathrm{ijc} .26031$

8 Masaki T, Matsuoka H, Kishiki T, Kojima K, Aso N, Beniya A, Tonari A, Takayama M, Abe N and Sunami E: Intraoperative radiotherapy for resectable advanced lower rectal cancer-final results of a randomized controlled trial (UMIN000021353). Langenbecks Arch Surg 405(3): 247-254, 2020. PMID: 32347365. DOI: 10.1007/s00423-020-01875-2

9 Strong MS, Vaughan CW, Kayne HL, Aral IM, Ucmakli A, Feldman M and Healy GB: A randomized trial of preoperative radiotherapy in cancer of the oropharynx and hypopharynx. Am J Surg 136(4): 494-500, 1978. PMID: 360853. DOI: 10.1016/ 0002-9610(78)90268-4

10 Kinoshita T, Uesaka K, Shimizu Y, Sakamoto H, Kimura W, Sunada S, Sunada S, Imaizumi T, Ozawa I, Okamoto A and Oda $\mathrm{T}$ : Effects of adjuvant intra-operative radiation therapy after curative resection in pancreatic cancer patients - results of a randomized study by 11 institutions in Japan. J Clin Oncol 27(15S): 231s, 2009

11 Saigusa S, Toiyama Y, Tanaka K, Yokoe T, Fujikawa H, Matsushita K, Okugawa Y, Inoue Y, Uchida K, Mohri Y and Kusunoki M: Inhibition of HGF/cMET expression prevents distant recurrence of rectal cancer after preoperative chemoradiotherapy. Int J Oncol 40(2): 583-591, 2012. PMID: 21922134. DOI: 10.3892/ijo.2011.1200 
12 Moncharmont C, Levy A, Guy JB, Falk AT, GuilbertM, Trone JC, Alphonse G, Gilormini M, Ardail D, Toillon RA, RodriguezLafrasse $\mathrm{C}$ and Magné N: Radiation-enhanced cell migration/ invasion process: a review. Crit Rev Oncol Hematol 92(2): 133-142, 2014. PMID: 24908570. DOI: 10.1016/j.critrevonc.2014.05.006

13 Vilalta M, Rafat $M$ and Graves EE: Effects of radiation on metastasis and tumor cell migration. Cell Mol Life Sci 73(16): 2999-3007, 2016. PMID: 27022944. DOI: 10.1007/s00018-0162210-5

14 Chen X, Liao R, Li D and Sun J: Induced cancer stem cells generated by radiochemotherapy and their therapeutic implications. Oncotarget 8(10): 17301-17312, 2017. PMID: 28038467.
15 Kopitz C, Gerg M, Bandapalli OR, Ister D, Pennington CJ, Hauser S, Flechsig C, Krell HW, Antolovic D, Brew K, Nagase H, Stangl $\mathrm{M}$, von Weyhern $\mathrm{CW}$, Brücher BL, Brand K, Coussens LM, Edwards DR and Krüger A: Tissue inhibitor of metalloproteinases1 promotes liver metastasis by induction of hepatocyte growth factor signaling. Cancer Res 67(18): 8615-8623, 2007. PMID: 17875701. DOI: 10.1158/0008-5472.CAN-07-0232

Received August 12, 2020

Revised August 28, 2020

Accepted August 31, 2020 